\title{
Distribution and composition of extracellular polymeric substances in membrane-aerated biofilm
}

\author{
Tinggang $\mathrm{Li}^{\mathrm{a}, \mathrm{b}}$, Renbi Bai ${ }^{\mathrm{c}}$, Junxin Liu ${ }^{\mathrm{a}, *}$ \\ a Research Center for Eco-Environmental Sciences, Chinese Academy of Sciences, Beijing 100085, People's Republic of China \\ ${ }^{\mathrm{b}}$ Institute of Environmental Science and Engineering, Nanyang Technological University, Singapore 637723, Singapore \\ ${ }^{\mathrm{c}}$ Division of Environmental Science and Engineering, National University of Singapore 117576, Singapore
}

\section{A R T I C L E I N F O}

\section{Article history:}

Received 16 June 2007

Received in revised form 5 February 2008

Accepted 18 February 2008

\section{Keywords:}

Composition

Distribution

Extracellular polymeric substances (EPS)

Membrane-aerated biofilm (MAB)

Stratification

Surface loading rate (SLR)

\begin{abstract}
A B S T R A C T
Extracellular polymeric substances (EPS) are one of the main components of the biofilm and perform important functions in the biofilm system. In this study, two membrane-aerated biofilms (MABs) were developed for the thin and thick biofilms under different surface loading rates (SLRs). Supplies of oxygen and substrates in the MAB were from two opposite directions. This counter diffusion of nutrients resulted in a different growth environment, in contrast to conventional biofilms receiving both oxygen and substrates from the same side. The compositions, distributions and physicochemical properties (solubility and bindability) of EPS in the MABs of different thicknesses under different SLRs were studied. The effect of dissolved oxygen (DO) concentration within the MAB on EPS properties and distribution was investigated. Experimental results showed the different biofilm thicknesses produced substantially different profiles of EPS composition and distribution. Soluble proteins were more dominant than soluble polysaccharides in the inner aerobic layer of the biofilms; in contrast, bound proteins were greater than bound polysaccharides in the outer anoxic or anaerobic layer of the biofilms. The biofilm-EPS matrix consisted mainly of bound EPS. Bound EPS exhibited a hump-shaped profile with the highest content occurring in an intermediate region in the thin MAB and relatively more uniformly in the one half of the biofilm close to the membrane side and then declined towards the biofilm-liquid interface in the thick MAB. The profiles of soluble EPS presented a similar declining trend from the membrane towards the outer region in both thin and thick MABs. The study suggested that not only EPS composition but also EPS distribution and properties (solubility and bindability) played a crucial role in controlling the cohesiveness and maintaining the structural stability and stratification of the MABs.
\end{abstract}

(c) 2008 Elsevier B.V. All rights reserved.

\section{Introduction}

Membrane-aerated biofilm reactor (MABR) has emerged as a novel biofilm technology for wastewater treatment (Brindle and Stephenson, 1996; Casey et al., 1999; Hibiya et al., 2003; LaPara et al., 2006). In a MABR, bubbleless oxygen supply is provided through a hydrophobic gas-permeable membrane to the other side of the membrane with biofilm attached and grown. Oxygen and nutrients are provided to the biofilm from the two opposite sides of the biofilm (see Fig. 1), as compared to the conventional biofilm grown on inert surfaces. The bubbleless aeration in a MABR avoids the problem of air striping loss of volatile organic compounds (VOCs) encountered in conventional aerobic bio-treatment processes (Cole et al., 2004; Pavasant et al., 1996; Rishell et al., 2004).

\footnotetext{
* Corresponding author. Tel.: +86 10 62849133; fax: +86 1062849133.

E-mail addresses: tglibj@hotmail.com (T. Li), jxliu@rcees.ac.cn (J. Liu).
}

Depending on the biofilm thickness and other operating conditions (such as oxygen supply pressure through the membrane, liquid recirculation rate in the reactor, and organic surface loading rate (SLR) to the biofilm on the membrane), the microbial species and activity through the thickness of the biofilm may vary and a membrane-aerated biofilm (MAB) where counter-gradients of oxygen and substrate exist can simultaneously perform degradation of carbonaceous compounds plus nitrification (at near the membrane side) and denitrification (at near the bulk liquid side) within a single MAB (Semmens et al., 2003; Terada et al., 2003).

Microbes often aggregate to form biofilms by fabricating a network consisting of cells and extracellular polymeric substances (EPS) (Geesey, 1982; Lazarova and Manem, 1995). EPS refer to a rich matrix of biopolymers, such as polysaccharides, proteins, nucleic acids, and others. The functions of EPS include the aggregation of bacterial cells, the formation of an active gel-like structure that maintains cell cohesion, stabilizes the biofilm structure, and pro- 


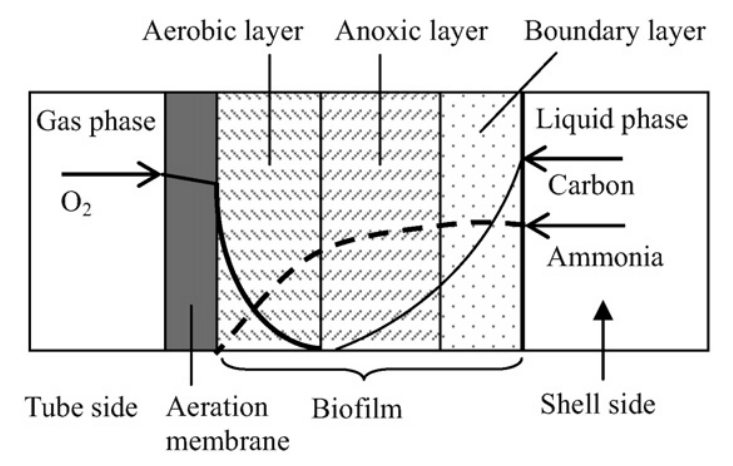

Fig. 1. Schematic diagram of the MABR showing the hypothetical biofilm structure and typical concentration profiles of the limiting substrates.

tects microbes against noxious environmental conditions (Dogsa et al., 2005; Laspidou and Rittmann, 2002; McSwain et al., 2005; Wingender et al., 1999).

The EPS content of a biofilm can vary in quantity and composition as a result of environmental factors and operational conditions. Environmental factors that have been reported to promote EPS yield include high levels of oxygen (Bayer et al., 1990), limited availability of nitrogen (Jarman et al., 1978), desiccation (Ophir and Gutnick, 1994), low temperature (Junkins and Doyle, 1992), and low pH (Ryu and Beuchat, 2004). Ahimou et al. (2007) reported that biofilm cohesiveness was strongly correlated with the biofilm polysaccharide content, which increased with the depth but not with the age of the biofilm. For biofilm from aerated biofilters fed with starch, Li et al. (2002) reported that polysaccharide was the primary constituent and protein was the minor one in the EPS extracts. In a rotating drum biofilm reactor fed with synthetic wastewater, Zhang and Bishop (2001) found that EPS content decreased with the biofilm depth and carbohydrate yield was much greater than protein yield in the EPS composition. However, there was also study showing contradictory result that biofilm predominantly contained protein as the major EPS component (Azeredo et al., 1999).

In spite of numerous research on EPS and its role in biofilm composition and structure, much less was even known on how operational conditions, such as SLR, and liquid recirculation rate of the reactor, influence the composition and distribution of EPS in a biofilm. Especially, little is currently understood about the characteristics (solubility and bindability) and distribution of EPS in a MAB where oxygen and substrate supplies follow two opposite concentration gradients. The effects of SLR and dissolved oxygen (DO) concentration profile in the biofilm on the EPS properties (such as soluble or bound) and their variations as a function of biofilm depth, although significant for understanding MAB behavior, remain almost entirely unknown.

In an early study, we investigated the biodegradation of acetonitrile (ACN) (a toxic nitrogen containing VOC) in a suspended growth bioreactor with adapted activated sludge consortium and showed the successful conversion of acetonitrile into acetamide, and further to acetic acid and ammonia (Li et al., 2007). In the present work, we studied the biodegradation of acetonitrile in a MABR under a specific oxygen supply and liquid recirculation rate but two different SLRs ( 5.66 and $10.54 \mathrm{~g} \mathrm{ACN} \mathrm{m}^{-2} \mathrm{~d}^{-1}$ ). EPS were extracted from the MAB to determine the soluble and bound contents of polysaccharide and protein. The compositions and distributions of EPS in the biofilms versus the thicknesses were examined. In addition, the effect of DO concentration within the MAB on EPS properties and distribution was also discussed.
Table 1

Summary of characteristics of MABRs and MABs

\begin{tabular}{|c|c|c|}
\hline & \multicolumn{2}{|c|}{ MABs grown at SLR1 or SLR2 } \\
\hline & Thin biofilm ${ }^{\mathrm{a}}$ & Thick biofilm ${ }^{\mathrm{b}}$ \\
\hline \multicolumn{3}{|l|}{ Characteristics of MABRs } \\
\hline ACN removal capacity $\left(\mathrm{g} \mathrm{ACN} \mathrm{m}^{-2} \mathrm{~d}^{-1}\right)$ & $5.66 \pm 0.09$ & $10.49 \pm 0.12$ \\
\hline ACN Removal efficiency (\%) & $100 \pm 8.3$ & $99.5 \pm 6.1$ \\
\hline TOC loading rate $\left(\mathrm{gC} \mathrm{m}^{-2} \mathrm{~d}^{-1}\right)$ & $3.24 \pm 0.07$ & $6.21 \pm 0.10$ \\
\hline TOC removal capacity $\left(\mathrm{gC} \mathrm{m}^{-2} \mathrm{~d}^{-1}\right)$ & $3.21 \pm 0.05$ & $5.97 \pm 0.08$ \\
\hline TOC removal efficiency (\%) & $99.1 \pm 5.6$ & $96.2 \pm 8.4$ \\
\hline TN loading rate $\left(\mathrm{g} \mathrm{N} \mathrm{m}^{-2} \mathrm{~d}^{-1}\right)$ & $2.15 \pm 0.02$ & $3.6 \pm 0.04$ \\
\hline TN removal capacity $\left(\mathrm{g} \mathrm{N} \mathrm{m}^{-2} \mathrm{~d}^{-1}\right)$ & $0.78 \pm 0.02$ & $3.06 \pm 0.09$ \\
\hline TN removal efficiency (\%) & $36.3 \pm 1.46$ & $85 \pm 2.15$ \\
\hline \multicolumn{3}{|l|}{ Characteristics of MABs } \\
\hline $\operatorname{VSS}\left(\mathrm{g} \mathrm{L}^{-1}\right)$ & $3.66 \pm 0.18$ & $6.86 \pm 0.32$ \\
\hline $\mathrm{O}_{2}$ at membrane $\left(\mathrm{mg} \mathrm{L}^{-1}\right)$ & $7.8 \pm 0.5$ & $7.6 \pm 0.6$ \\
\hline $\begin{array}{l}\text { Location of maximum respiratory } \\
\text { activity }(\mu \mathrm{m})^{c}\end{array}$ & $300 \pm 25$ & $500 \pm 40$ \\
\hline Final thickness $(\mu \mathrm{m})$ & $950 \pm 165$ & $1600 \pm 270$ \\
\hline Average EPS ( $\mathrm{mg} \mathrm{g}^{-1}$ VSS) & 129.8 & 100.8 \\
\hline Average dry cell mass $\left(\mathrm{mg}\right.$ cell $\mathrm{cm}^{-2}$ ) & 4.1 & 7.9 \\
\hline $\begin{array}{l}\text { Average ratio of live cells to entire cells } \\
\text { in aerobic zone }\end{array}$ & 0.96 & 0.93 \\
\hline $\begin{array}{l}\text { Average ratio of live cells to entire cells } \\
\text { in anoxic zone }\end{array}$ & 0.90 & 0.87 \\
\hline $\begin{array}{l}\text { Average ratio of live cells to entire cells } \\
\text { in anaerobic zone }\end{array}$ & - & 0.88 \\
\hline
\end{tabular}

a Thin biofilm grown at SLR1.

b Thick biofilm grown at SLR2.

c Location of maximum respiratory activity is relative to the membrane.

\section{Materials and methods}

\subsection{Reactor configuration and operational conditions}

Two identical laboratory-scale MABRs were operated for 6 months to develop MABs using ACN as the sole initial carbon and nitrogen sources. Each of the MABRs contained a membrane module consisting of microporous polypropylene hollow fibers $(320 \mu \mathrm{m}$ o.d. and $200 \mu \mathrm{m}$ i.d.) in a dead-end configuration. The working volume of each reactor was $1.42 \mathrm{~L}$ with packed membranes at a specific surface area of $84.5 \mathrm{~m}^{2} \mathrm{~m}^{-3}$. The membrane module was supplied with oxygen at $8.6 \mathrm{~mL} \mathrm{~min}^{-1}$ under a trans-membrane pressure of 2 psi and the reactor was operated at a HRT of $30 \mathrm{~h}$. A centrifugal pump was used to recirculate the liquid in the reactor (at a rate of 3.5 $\mathrm{L} \mathrm{min}^{-1}$ ) to achieve a mean upflow fluid velocity of $12 \mathrm{~cm} \mathrm{~s}^{-1}$. MABs were developed separately in the two reactors at an average SLR of 5.66 (SLR1) or $10.54 \mathrm{~g} \mathrm{ACN} \mathrm{m}^{-2} \mathrm{~d}^{-1}$ (SLR2), respectively. Other relevant information of the MABRs and MABs are summarized in Table 1 . The MABRs were inoculated with acclimated activated sludge microbial consortium as prepared and detailed elsewhere (Li et al., 2007).

Biofilms were then harvested from the reactors after 6 months development. Sample preparation was performed according to the protocol described by Cole et al. (2004) and LaPara et al. (2006). The biofilm attached to the membrane at different locations were excised with a razor blade and immediately frozen at $-15^{\circ} \mathrm{C}$. Then a series of biofilm slices of a $200 \mu \mathrm{m}$ thickness were prepared from the frozen biofilm sample using a combined cryostat/microtome (CM 3050, Germany) at $-20^{\circ} \mathrm{C}$. The biofilm mass from each slice was placed in a sterile centrifuge tube and stored at $-20^{\circ} \mathrm{C}$ for further analysis.

\subsection{Analytical methods}

Mixed liquor suspended solid (MLSS) and volatile suspended solid (VSS) were measured according to the standard methods (APHA, 1998). Total organic carbon (TOC) and total nitrogen (TN) 
were determined by a TOC-VCSH plus nitrogen analyzers (Shimadhu, Japan). Ammonia, nitrite and nitrate were analyzed with Hach test kits by a UV-vis Spectrophotometer (DR 5000, Hach, USA). Acetonitrile was measured through gas chromatography (Agilent $6890 \mathrm{~N}$, USA) as previously described (Li et al., 2007). Biofilm thickness was determined using a light microscope ( $\mathrm{VH}-$ $\mathrm{Z75}$, Keyence, Japan) through the non-invasive and non-destructive method. DO concentration profiles were determined using a Clark-type microelectrode (Unisense, Aarhus, Denmark) with a tip diameter of $10 \mu \mathrm{m}$ and a response time of less than $5 \mathrm{~s}$. The DO microelectrode was inserted into the biofilm using a micromanipulator (MMO-223, Japan) at a depth step of $10 \mu \mathrm{m}$.

The EPS extraction method was modified from those of Liu and Fang (2002), Azeredo et al. (1999) and Zhang et al. (1999) for improving extraction. The biofilm mass from each slice was prepared into a $5 \mathrm{~mL}$ suspension with the addition of sterile deionized water. The suspension was centrifuged $\left(4000 \times \mathrm{g}, 10 \mathrm{~min}, 4^{\circ} \mathrm{C}\right)$ and the supernatant was decanted into another sterile tube and recentrifuged $\left(13,200 \times g, 20 \mathrm{~min}, 4^{\circ} \mathrm{C}\right)$ to ensure complete removal of the suspended solids. The resultant supernatant by this physical extraction contained soluble polysaccharide and soluble protein, and was analyzed for soluble EPS content. The biofilm solid flocs in the tube were resuspended with distilled water to obtain again another $5 \mathrm{~mL}$ suspension. Then, $6 \mu \mathrm{L}$ formaldehyde (37\%) was added first into the suspension for $1 \mathrm{~h}$ at $4{ }^{\circ} \mathrm{C}$, followed by $0.5 \mathrm{~mL} \mathrm{NaOH}(1 \mathrm{~N})$ for another $3 \mathrm{~h}$ at $4{ }^{\circ} \mathrm{C}$. The suspension was centrifuged $(13,200 \times \mathrm{g}, 20 \mathrm{~min}$, $4{ }^{\circ} \mathrm{C}$ ) and the supernatant from this chemical extracting method, containing bound polysaccharide and bound protein, was analyzed for bound EPS content. The total EPS were taken as the sum of the soluble and bound EPS. Polysaccharide concentrations were quantified by the phenol-sulfuric acid method with glucose as a standard (Dubois et al., 1956). Protein concentrations were determined using the Bradford coomassie Blue method with Bovine Serum Albumin (BSA) as a standard (Bradford, 1976). All samples were determined the concentrations using a UV-vis spectrophotometer (Jasco V-550, Japan) at the wavelength of $490 \mathrm{~nm}$ for polysaccharide or at the wavelength of $595 \mathrm{~nm}$ for protein.

Respiratory activity was measured by the method of iodonitrotetrazolium chloride (INT) reduction to INT-formazan as described by others (LaPara et al., 2006; von Mersi and Schinner, 1991). INT-formazan concentrations were quantified using the UV-vis spectrophotometer at the wavelength of $464 \mathrm{~nm}$.

Bacterial viability was examined with the LIVE/DEAD double staining kit (BacLight, Molecular Probes, Eugene, OR). Biofilm cell suspensions $\left(1 \times 10^{5}\right.$ to $1 \times 10^{6}$ cells $\left.\mathrm{mL}^{-1}\right)$ of $200 \mu \mathrm{L}$ from aerobic, anoxic or anaerobic zone in MABs was stained with $100 \mu \mathrm{L}$ of the stain mixture $(8 \mu \mathrm{M}$ of the permeable stain acetoxymethyl ester of calcein (Calcein-AM) and $4 \mu \mathrm{M}$ of non-permeable stain propidium iodide (PI)) in a $1.5 \mathrm{~mL}$ micro-tube at $37^{\circ} \mathrm{C}$ in the dark for $15 \mathrm{~min}$. The samples were rinsed twice with the phosphate buffer saline for $1 \mathrm{~min}$ each and were mounted on the glass slides for the analysis. The fluorescence dyes used for staining of live and dead cells were Calcein-AM (green cells are alive) and PI (red cells are dead). The stained cells were determined by a confocal laser scanning microscopy (Olympus, FLUOVIEW, Japan) equipped with double channels for LIVE/DEAD cells. The excitation/emission maxima for Calcein-AM and PI are at 490/515 and 537-545/617-620 nm for viable and dead cells.

\section{Results}

\subsection{MABR performance and MAB characteristics}

From the results summarized in Table 1 , it is clear that both MABRs performed well at SLR1 and SLR2 in terms of ACN removal,

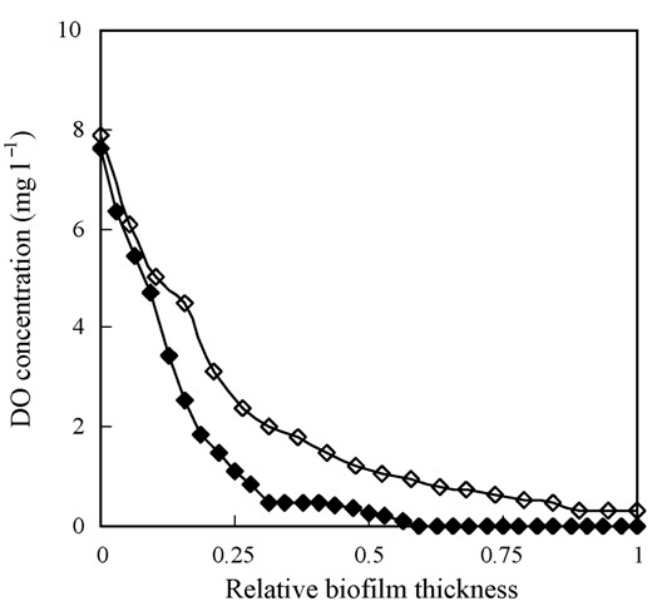

Fig. 2. Dissolved oxygen concentration profiles in MABs. ( $\diamond)$, Thin biofilm; $(\diamond)$, thick biofilm. Relative biofilm thickness is defined as the fraction of a thin biofilm of $960 \mu \mathrm{m}$ (at SLR1) or a thick biofilm of $1600 \mu \mathrm{m}$ (at SLR2). Biofilm thickness was calculated from membrane surface to biofilm-liquid interface.

but the performance differed in the removal efficiencies of TOC and TN. TN removal efficiency was much higher in the MAB grown at SLR2 than that in the MAB grown at SLR1. The MAB grown at SLR1 developed an average VSS of $3.66 \mathrm{~g} \mathrm{~L}^{-1}$ and a final biofilm thickness of $950 \mu \mathrm{m}$ (thin biofilm), in contrast to an average VSS of $6.86 \mathrm{~g} \mathrm{~L}^{-1}$ and a final biofilm thickness of $1600 \mu \mathrm{m}$ (thick biofilm) for the MAB grown at SLR2. The average EPS content was greater for the MAB at SLR1 than at SLR2. The total dry cell mass of the MAB developed at SLR2 was 1.93 times that developed at SLR1. The thicker biofilm developed at SLR2 exhibited a slightly lower viable biomass ratio than the thinner biofilm at SLR1 (see Table 1).

DO concentrations in the biofilms were at a similar level at near the membrane/biofilm interface and then declined with the biofilm thickness for the MABs at the two SLRs (Fig. 2). For the thick MAB grown at SLR2, the DO in the bulk liquid and in about $40 \%$ of the outer biofilm (on the liquid side) was around zero, i.e., anoxic or anaerobic region was obtained in the MAB at higher SLR. Nitrification rate was much higher in the thinner MAB grown at SLR1 and the nitrate concentration in the effluent was up to $91.9 \mathrm{mg} \mathrm{L}^{-1}$. Denitrification occurred in the thicker MAR at SLR2, resulting in a much higher TN removal for the effluent (Table 1). In other words, the aerobic/anoxic or aerobic/anoxic/anaerobic zones were successfully formed within the MABs under different SLRs. Ammonia-oxidizing bacteria were found in the biofilm near the membrane side, whereas acetonitrile-degrading bacteria proliferated mainly in the middle and outer regions of biofilms; denitrifying bacteria were found in the anoxic and anaerobic outer regions of the MAB grown at SLR2 but not anywhere in the MAB grown at SLR1 (Li et al., 2008).

\subsection{EPS characteristics}

EPS were characterized in terms of soluble or bound polysaccharide and protein. It was found that both soluble polysaccharide and protein declined similarly with the relative biofilm thickness in the thin MAB (at SLR1) or thick MAB (at SLR2) and soluble protein was always much greater than soluble polysaccharide (being about 1.9 times) in both types of MABs (see Fig. 3 ).

Bound protein was greater than bound polysaccharide in thin biofilm (at SLR1) and bound protein was also relatively constant throughout the thin biofilm. For the thick biofilm (at SLR2), bound protein was greater than polysaccharide in most of the biofilm on the liquid side but was smaller in a small portion of the biofilm 


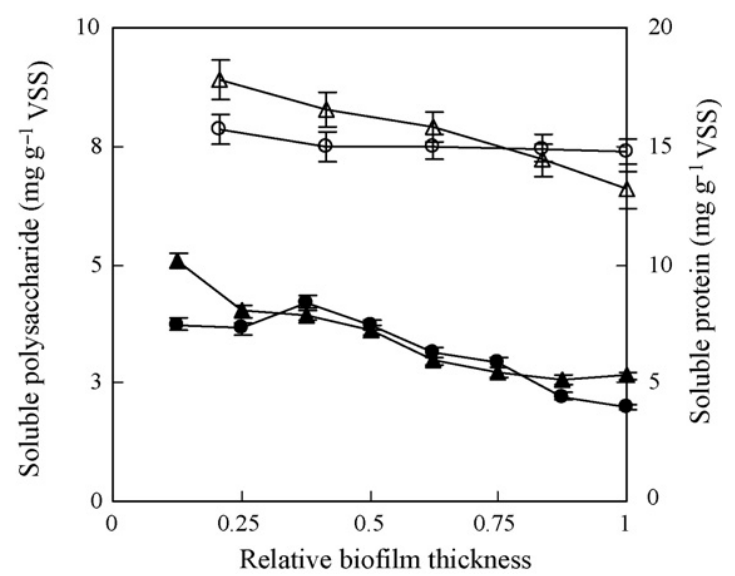

Fig. 3. Distributions of soluble polysaccharide and soluble protein in EPS compositions in MABs at surface loading rates. $(\triangle)$, Soluble polysaccharide (thin biofilm); $(\bigcirc)$, soluble protein (thin biofilm); $(\mathbf{\Lambda})$, soluble polysaccharide (thick biofilm); $(\mathbf{0})$, soluble protein (thick biofilm). Vertical bars represent the standard deviations calculated from triplicates. The definition of relative biofilm thickness is consistent with that in Fig. 2.

on the membrane side. Although bound polysaccharide monotonically decreased with the biofilm thickness from the membrane side towards the liquid side, the bound protein showed an obvious hump-shape distribution in the thick MAB. It is also clear that bound protein in the thin biofilm was greater than that in the thick biofilm and bound polysaccharide in the thin biofilm was greater than that in the thick biofilm for the major portion of the biofilm on the liquid side (see Fig. 4).

Similarly, the total protein and total polysaccharide of the EPS for both the thin and thick MABs in Fig. 5 exhibited similar variation patterns within the biofilms to those of the bound components of EPS shown in Fig. 4. Overall, the contents of total protein and total polysaccharide in the thin biofilm were both generally greater than those in the thick biofilm. In the thin biofilm, the total protein was more dominant for the EPS than the total polysaccharide. For the thick biofilm, total polysaccharide was more significant in the EPS for about one third of the biofilm on the membrane side but total protein was more dominant in the EPS for the rest of about two thirds of the biofilm on the liquid side.

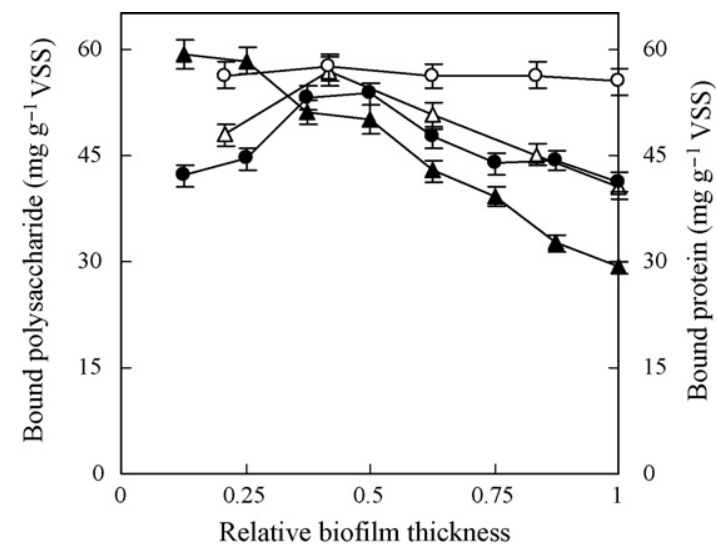

Fig. 4. Distributions of bound polysaccharide and bound protein in EPS compositions in MABs at surface loading rates. $(\triangle)$, Bound polysaccharide (thin biofilm); $(\bigcirc)$, bound protein (thin biofilm); ( $\mathbf{\Lambda})$, bound polysaccharide (thick biofilm); $(\boldsymbol{\bullet})$, bound protein (thick biofilm). Vertical bars represent the standard deviations calculated from triplicates. The definition of relative biofilm thickness is consistent with that in Fig. 2.

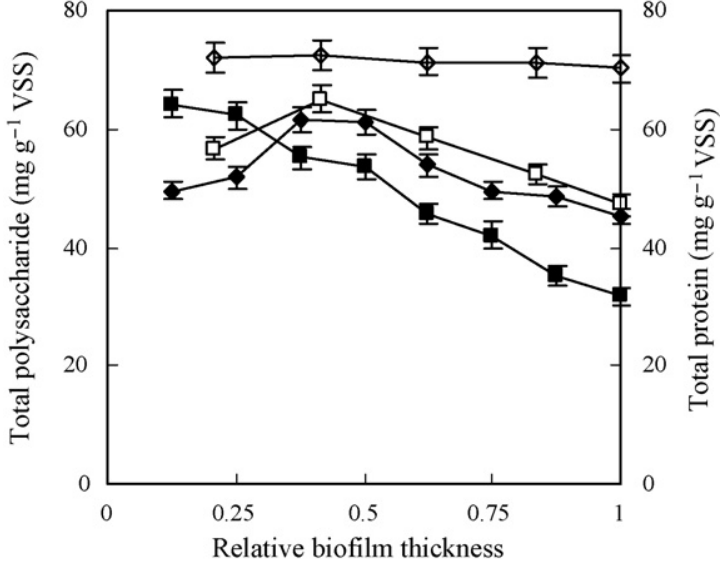

Fig. 5. Distributions of total polysaccharide and total protein in EPS compositions in MABs at surface loading rates. $(\diamond)$, Total protein (thin biofilm); ( $\square$ ), total polysaccharide (thin biofilm); $(\checkmark)$, total protein (thick biofilm); $(\boldsymbol{\square})$, total polysaccharide (thick biofilm). Vertical bars represent the standard deviations calculated from triplicates. The definition of relative biofilm thickness is consistent with that in Fig. 2.

EPS have been recognized as a major constituent of a biofilm and, according to the physicochemical properties (solubility and bindability), EPS can be classified into soluble and bound EPS. The different biofilm thicknesses (at SLR1 and SLR2) produced substantially different EPS composition and distribution profiles (Fig. 6). For the thin MAB, bound EPS exhibited a hump-shaped profile with the highest content occurring in an intermediate region. Whereas, for the thick MAB, bound EPS was distributed relatively more uniformly in the one half of the biofilm close to the membrane side and then declined towards the biofilm-liquid interface (Fig. 6). Furthermore, the profiles of soluble EPS presented a similar trend in both thin and thick MABs. Soluble EPS gradually decreased from the membrane towards the outer region of MABs. However, the content of soluble EPS in the thin MAB was two times higher than that of the thick MAB (Fig. 6). Collectively, the distributions of total EPS exhibited a similar trend as compared to those of bound EPS, with an about 17\% increase in total EPS content with the decrease in biofilm thickness (Fig. 7).

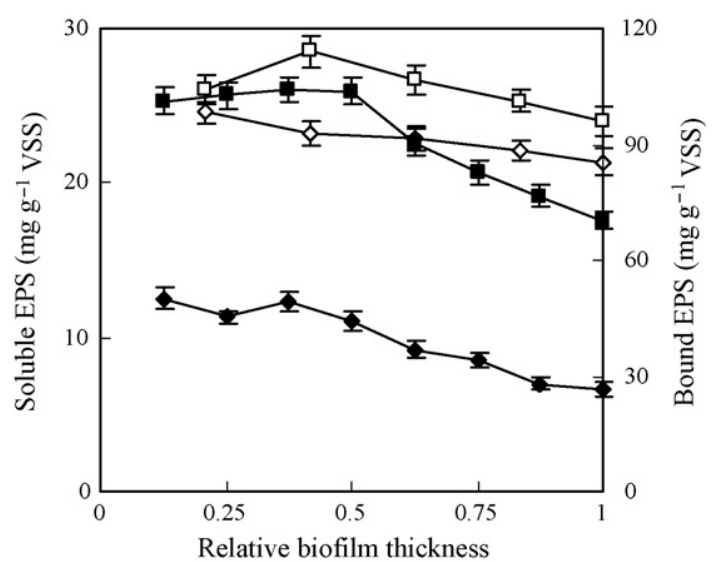

Fig. 6. Soluble and bound EPS profiles in MABs at surface loading rates. ( $\square$ ), Bound EPS (thin biofilm); $(\diamond)$, soluble EPS (thin biofilm); $(\mathbf{\square})$, bound EPS (thick biofilm); $(\downarrow)$, soluble EPS (thick biofilm). Vertical bars represent the standard deviations calculated from triplicates. The definition of relative biofilm thickness is consistent with that in Fig. 2. 


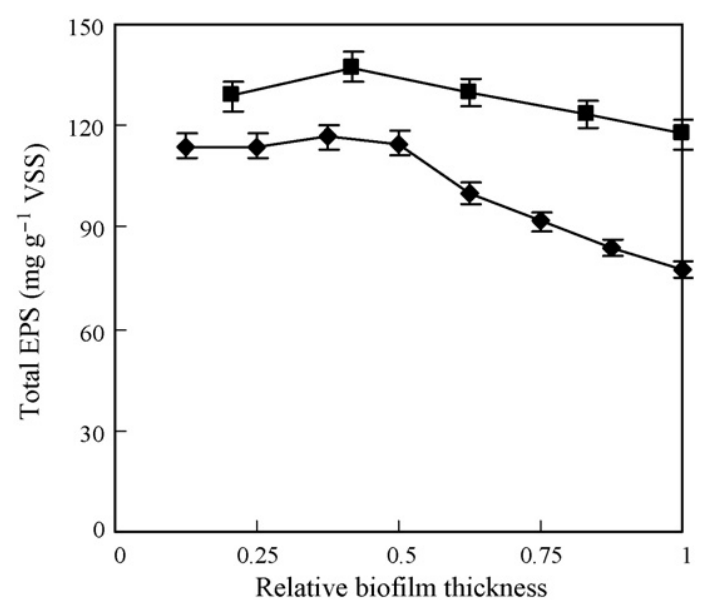

Fig. 7. Distributions of total EPS in MABs at surface loading rates. (ם), Thin biofilm; $(\downarrow)$, thick biofilm. Vertical bars represent the standard deviations calculated from triplicates. The definition of relative biofilm thickness is consistent with that in Fig. 2.

\section{Discussion}

Results in this study demonstrated the heterogeneous composition and distribution of EPS in MABs versus the relative biofilm thickness and under different SLRs. To our knowledge, this is the first report in the literature on the solubility and bindability of EPS in MABs in which the limiting substrates are supplied from the opposite sides of the biofilm. Bound EPS (i.e., bound polysaccharide and bound protein) appeared to play more important role in the biofilms than the soluble EPS, and up to 81 to $92 \%$ of the total EPS was associated with bound EPS. It should be noted that bound EPS are more hydrophobic and non-readily biodegradable (Hirst et al., 2003; Laspidou and Rittmann, 2002; Wang et al., 2005), and hence it would favor the adhesion to the biomass and seems to be served as the backbone of the biofilm structure, thus improving the stability of biofilms (Figs. 4 and 6).

Furthermore, more bound and soluble EPS were secreted in the thin MAB at a lower SLR, as compared to the thick MAB grown under a relatively higher SLR (Table 1 and Fig. 6). This may indicate that a nutrient-deficient situation would induce the more production of the EPS. It has been reported that compared to a balanced culture, ten times more soluble EPS were secreted in nutrient deficiency culture (Aquino and Stuckey, 2003). Sivan et al. (2006) reported that with carbon-starved cultures, bacterial surfaces became more hydrophobic and more adhesive than with non-starved cultures, while nitrogen starvation had only a minor effect on the cultures.

In this study, The MAB system is complex, with the region nearest the membrane being rich in oxygen but low in substrate concentrations, whereas the outer region of the biofilm being void of oxygen but rich in substrate concentrations. As the biofilm thickness increased (as a result of the increased SLR), resistance diffusion of oxygen and the nutrient diffusion into the biofilm increased, resulting in the stratification of active regions in the MABs. Consequently, the region near the membrane would be highly aerobic but the region next to the bulk liquid (wastewater) could be fully anaerobic in the thick biofilm grown at SLR2. These changing growth conditions within the biofilm can influence microbial growth rate, and potentially the EPS production. Results presented earlier show that soluble proteins were more dominant than soluble polysaccharides in the inner aerobic layer of the biofilms, and, on the contrary, bound proteins were greater than bound polysaccharides in the outer anoxic or anaerobic layer of the biofilms. In addition, more EPS were generated in the aerobic region than in the anoxic or anaerobic regions. In literature, some studies reported high levels of oxygen promoting the production of polysaccharides (Bayer et al., 1990; Ahimou et al., 2007), but others (Applegate and Bryers, 1991) showed oxygen-limited biofilms exhibiting higher EPS production, suggesting the significance to examine factors that affect EPS production and its role in biofilm structure in research based on not only specific EPS components but also structural distribution and properties (solubility and bindability) of EPS.

A better understanding of the factors controlling the stratification of MABs is important to improve and optimize its application. EPS yield accumulated in the aerobic region of the MAB where autotrophic ammonia-oxidizing bacteria lived, and which in turn favored the attachment of ammonia-oxidizing bacteria grown in the MAB. EPS declined towards the anoxic outer region of the MAB where heterotrophic bacteria (acetonitrile-degrading bacteria or denitrifying bacteria) lived (Fig. 7). Since soluble EPS are easily utilized by microbial communities (Hirst et al., 2003; Laspidou and Rittmann, 2002), EPS in outer region of MABs may be more available to bacteria, and possibly provided partial carbon source for the heterotrophic bacteria (Figs. 3 and 6). Another explanation is that inert biomass. The denitrifier and ACN-degrading bacteria, having a slower growth rate, it would be expected that the anoxic/anaerobic region of the biofilm to be more enriched in inert biomass. As time advanced, the bound EPS formed in that region from the bacteria and were converted into inert biomass (as a result of decay) that would turn to soluble EPS with time as a result of its hydrolysis, thus resulting in less EPS (Laspidou and Rittmann, 2002, 2004). In addition, a thicker biofilm favored to allow both nitrification and denitrification to proceed as compared to a thinner biofilm (Table 1), but excessively thick biofilm-EPS hindered the mass transfer of ammonia into the inner region of the biofilm where ammonia-oxidizing rate was only $86 \%$ (data not shown).

In conclusion, our results suggest that EPS yield, especially bound EPS yield, may be triggered with decrease in SLR or aeration. The biofilm-EPS matrix consisted mainly of bound EPS (in terms of bound polysaccharide and bound protein) in MABs. The study demonstrated that not only EPS composition but also EPS distribution and properties (solubility and bindability) played a crucial role in controlling the cohesiveness and maintaining the structural stability and stratification of the MABs. This research should also enhance the insight to explore the biofilm behavior. Conditions for inducing to secrete more bound EPS could be applied for the microbial aggregates for bioremediation of hazardous wastes, or the protection of bacterial cells against solvent deterioration.

\section{References}

Ahimou, F., Semmens, M.J., Haugstad, G., Novak, P.J., 2007. Effect of protein, polysaccharide, and oxygen concentration profiles on biofilm cohesiveness. Appl. Environ. Microbiol. 73, 2905-2910.

APHA-AWWA-WEF, 1998. Standard methods for examination of water and wastewater, 20th ed. APHA, AWWA, and WEF, Washington, DC.

Applegate, D.H., Bryers, J.D., 1991. Effects of carbon and oxygen limitation and calcium concentration on biofilm removal processes. Biotechnol. Bioeng. 37, 17-25.

Aquino, S.F., Stuckey, D.C., 2003. Production of soluble microbial products (SMP) in anaerobic chemostats under nutrient deficiency. J. Environ. Eng. 129, 1007-1014.

Azeredo, J., Lazarvo, V., Oliveira, R., 1999. Methods to extract the exopolymeric matrix from biofilms: a comparative study. Water Sci. Tech. 39, 243-250.

Bayer, A.S., Eftekhar, F., Tu, J., Nast, C.C., Speert, D.P., 1990. Oxygen-dependent upregulation of mucoid exopolysaccharide (alginate) production in Pseudomonas aeruginosa. Infect. Immun. 58, 1344-1349.

Bradford, M.M., 1976. A rapid and sensitive method for the quantification of microgram quantities of protein utilizing the principle of protein-dye binding. Analyt. Biochem. 72, 248-254.

Brindle, K., Stephenson, T., 1996. The application of membrane biological reactors for the treatment of wastewaters. Biotechnol. Bioeng. 49, 601-610. 
Casey, E., Glennon, B., Hamer, G., 1999. Oxygen mass transfer characteristics in a membrane-aerated biofilm reactor. Biotechnol. Bioeng. 62, 183-190.

Cole, A.C., Semmens, M.J., LaPara, T.M., 2004. Stratification of activity and bacterial community structure in biofilms grown on membranes transferring oxygen. Appl. Environ. Microbiol. 70, 1982-1989.

Dogsa, I., Kriechbaum, M., Stopar, D., Laggnerz, P., 2005. Structure of bacterial extracellular polymeric substances at different $\mathrm{pH}$ values as determined by SAXS. Biophys. J. 83, 2711-2720.

Dubois, M.J., Gills, K.A., Hamilton, J.K., Reber, P.A., Smith, F., 1956. Colorimetric method for determination of sugars and related substances. Analyt. Chem. 28 , 350-356.

Geesey, G.G., 1982. Microbial exopolymers: ecological and economic considerations. ASM News 48, 9-14.

Hibiya, K., Terada, A., Tsuneda, S., Hirata, A., 2003. Simultaneous nitrification and denitrification by controlling vertical and horizontal microenvironment in membrane-aerated biofilm reactor. J. Biotechnol. 100, 23-32.

Hirst, C.N., Cyr, H., Jordan, I.A., 2003. Distribution of exopolymeric substances in the littoral sediments of an oligotrophic lake. Microb. Ecol. 46, 23-32.

Jarman, T.R., Deavin, L., Slocombe, S., Righelato, R.C., 1978. Investigation of the effect of environmental conditions on the rate of exopolysaccharide synthesis in Azotobacter vinelandii. J. Gen. Microbiol. 107, 59-64.

Junkins, A.D., Doyle, M.P., 1992. Demonstration of exopolysaccharide production by enterohemorrhagic Escherichia coli. Curr. Microbiol. 25, 9-17.

LaPara, T.M., Cole, A.C., Shanahan, J.W., Semmens, M.J., 2006. The effects of organic carbon, ammoniacal-nitrogen, and oxygen partial pressure on the stratification of membrane-aerated biofilms. J. Ind. Microbiol. Biotechnol. 33, 315-323.

Laspidou, C.S., Rittmann, B.E., 2002. A unified theory for extracellular polymeric substances, soluble microbial products, and active and inert biomass. Water Res. 36, 2711-2720.

Laspidou, C.S., Rittmann, B.E., 2004. Modeling the development of biofilm density including active bacteria, inert biomass, and extracellular polymeric substances. Water Res. 38, 3349-3361.

Lazarova, V., Manem, J., 1995. Biofilm characterization and activity analysis in water and wastewater treatment. Water Res. 29, 2227-2245.

Li, J., Luan, Z., Zhu, B., Gong, X., Peng, D., 2002. Effects of colloidal organic matter on nitrification and composition of extracellular polymeric substances in biofilms. J. Chem. Technol. Biotechnol. 77, 1333-1339.

Li, T.G., Bai, R.B., Liu, J.X., 2008. Membrane-aerated biofilm reactor for the treatment of acetonitrile wastewater. Environ. Sci. Technol. 42, 2099-2104.

Li, T.G., Liu, J.X., Bai, R.B., Ohandja, D.G., Wong, F.S., 2007. Biodegradation of organonitriles by adapted activated sludge consortium with acetonitrile-degrading microorganisms. Water Res. 41, 3465-3473.
Liu, H., Fang, H.H.P., 2002. Extraction of extracellular polymeric substances (EPS) of sludges. J. Biotechnol. 95, 249-256.

McSwain, B.S., Irvine, R.L., Hausner, M., Wilderer, P.A., 2005. Composition and distribution of extracellular polymeric substances in aerobic flocs and granular sludge. Appl. Environ. Microbiol. 71, 1051-1057.

Ophir, T., Gutnick, D.L., 1994. A role for exopolysaccharide in the protection of microorganisms from desiccation. Appl. Environ. Microbiol. 60, 740745.

Pavasant, P., Freitas dos Santos, L.M., Pistikopoulos, E.N., Livingston, A.G., 1996. Prediction of optional biofilm thickness for membrane-attached biofilms growing in an extractive membrane bioreactor. Biotechnol. Bioeng. 52, 373386.

Rishell, S., Casey, E., Glennon, B., Hamer, G., 2004. Mass transfer analysis of a membrane-aerated reactor. Biochem. Eng. J. 18, 159-167.

Ryu, J.H., Beuchat, L.R., 2004. Factors affecting production of extracellular carbohydrate complexes by Escherichia coli 0157:H7. Int. J. Food Microbiol. 95, 189-204.

Semmens, M.J., Dahm, K., Shanahan, J., Christianson, A., 2003. COD and nitrogen removal by biofilms growing on gas permeable membranes. Water Res. 37, 4343-4350

Sivan, A., Szanto, M., Pavlov, V., 2006. Biofilm development of the polyethylenedegrading bacterium Rhodococcus rubber. Appl. Microbiol. Biotechnol. 72, 346-352.

Terada, A., Hibiya, K., Nagai, J., Tsuneda, S., Hirata, A., 2003. Nitrogen removal characteristics and biofilm analysis of a membrane-aerated biofilm reactor applicable to high-strength nitrogenous wastewater treatment. J. Biosci. Bioeng. 95, 170-178.

von Mersi, W., Schinner, F., 1991. An improved and accurate method for determining the dehydrogenase activity of soils with iodonitrotetrazolium chloride. Biol. Fert. Soils 11, 216-220.

Wang, Z.W., Liu, Y., Tay, J.H., 2005. Distribution of EPS and cell surface hydrophobicity in aerobic granules. Appl. Microbiol. Biotechnol. 69, 469-473.

Wingender, J., Neu, T.R., Flemming, H.C., 1999. What are bacterial extracellular polymeric substances? In: Wingender, J., Neu, T.R., Flemming, H.C. (Eds.), Microbial Extracellular Polymeric Substances: Characterization, Structure, and Function. Springer, Berlin, Germany, pp. 1-20.

Zhang, X.Q., Bishop, P.L., 2001. Spatial distribution of extracellular polymeric substances in biofilms. J. Environ. Eng. ASCE 127, 850-856.

Zhang, X.Q., Bishop, B.L., Kinkle, B.K., 1999. Comparison of extraction methods for quantifying extracellular polymers in biofilms. Water Sci. Technol. 39, 211-218. 